\title{
Decreasing significance of left ventricular dysfunction and reoperative surgery in predicting coronary artery bypass grafting-associated mortality: A twelve-year study
}

Piroze M. Davierwala, MD

Manjula Maganti, MSc

Terrence M. Yau, MD, MSc

From the Division of Cardiovascular Surgery, Toronto General Hospital, University Health Network, Department of Surgery, and the Heart and Stroke Foundation/Richard Lewar Centre of Excellence, University of Toronto, Toronto, Ontario, Canada.

Received for publication Feb 25, 2003; revisions requested March 18, 2003; revisions received May 4, 2003; accepted for publication June 4, 2003.

Address for reprints: Terrence M. Yau, MD, MSc, Division of Cardiovascular Surgery, Toronto General Hospital, University Health Network, 13EN-239, 200 Elizabeth St, Toronto, Ontario, Canada, M5G 2C4 (E-mail: terry.yau@utoronto.ca).

J Thorac Cardiovasc Surg 2003;126: $1335-44$

Copyright $\odot 2003$ by The American Association for Thoracic Surgery

$0022-5223 / 2003 \$ 30.00+0$

doi:10.1016/S0022-5223(03)00936-X
Objectives: Patients undergoing coronary artery bypass grafting are older and have greater comorbidity than those operated on previously. We evaluated the changes in the predictors of in-hospital mortality among patients undergoing coronary artery bypass grafting during the last 12 years.

Methods: Data on demographic characteristics, preoperative risk factors, operative variables, and hospital outcomes were collected prospectively for all patients undergoing isolated coronary artery bypass grafting at a single institution from January 1, 1990, to December 31, 2001. To examine the effect of time on patient risk profiles and outcomes, we divided patients into three groups according to year of operation $(1990-1993 \mathrm{n}=5171,1994-1997 \mathrm{n}=5977,1998-2001 \mathrm{n}=6893)$.

Results: In-hospital mortality declined from $2.4 \%$ (1990-1993) to 1.2\% (1998-2001, $P<.0001)$. Left ventricular dysfunction, increasing age, female gender, hypertension, diabetes, cardiogenic shock, congestive heart failure, peripheral vascular disease, reoperative coronary artery bypass grafting, left main disease, and urgent surgery independently predicted in-hospital mortality in the entire cohort of 18,041 patients. Severe left ventricular dysfunction was the most significant predictor of in-hospital mortality in the 12-year cohort, but it had a declining influence with time (1990-1993 odds ratio 7.1, 1994-1997 odds ratio 5.1, 1998-2001 not statistically significant) because of improving outcomes. Reoperative coronary artery bypass grafting similarly decreased in significance as a predictor of mortality. Emergency coronary artery bypass grafting was performed less frequently in recent years, but the requirement for emergency surgery carried an increasing odds ratio for mortality.

Conclusions: Despite increasing patient age and comorbidity, improvements in perioperative management have reduced the significance of severe left ventricular dysfunction and reoperative coronary artery bypass grafting but not emergency surgery as predictors of in-hospital mortality.

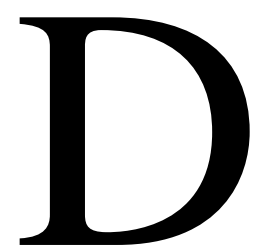

uring the last decade, an increasingly older and sicker population of patients has been referred to cardiac surgeons for coronary artery bypass grafting $(\mathrm{CABG}) .{ }^{1-5}$ This progressive increase in the burden of atherosclerosis and of other comorbidities may be partly attributed to concomitant advances in medical management and interventional cardiology. Despite the increasing patient age and risk factors, however, in-hospital mortality has progressively declined. This trend was well demonstrated by Christakis and colleagues ${ }^{6}$ and Ugnat and Naylor ${ }^{7}$ in the 1980s and by Abramov and coworkers, ${ }^{2}$ Noyez and colleagues, ${ }^{3}$ Hannan and associates, ${ }^{8}$ and Ghali and coworkers ${ }^{9,10}$ during the last decade. Studies that have focused on older patients undergoing $\mathrm{CABG}$ have also demonstrated a reduction in in-hospital mortality during the last decade. ${ }^{11,12}$ 
There have been tremendous efforts to develop risk stratification models to provide more accurate prediction of mortality and morbidity among patients undergoing CABG, culminating in the development of the Society of Thoracic Surgeons National Database. These predicted risks can then be used in patient counseling, to decide between alternative therapies, and to direct efforts to improve outcomes in high-risk subgroups. ${ }^{13}$ As perioperative management advances, however, predictive models become outdated and inaccurate. It is therefore essential to analyze evolutionary trends in the patient population with time, as well as changes in the predictors of outcomes, to ensure that current decisions are still based on valid data. We therefore analyzed our experience during a 12-year period with patients undergoing isolated CABG to evaluate changes in their risk profiles, document their outcomes, and determine changes in the independent predictors of in-hospital mortality.

\section{Methods}

\section{Data Source}

Clinical, operative, and outcome data were collected prospectively in a computerized database for 18,041 consecutive patients undergoing isolated CABG between January 1, 1990, and December 31, 2001, at Toronto General Hospital. Patients undergoing concomitant surgery for valve or congenital heart disease, aortic root pathology, ventricular aneurysms, or arrhythmias were excluded from this study.

\section{Outcome and Explanatory Variables}

Our primary outcome in this study was in-hospital mortality, which was defined as any postoperative death in hospital. Core baseline explanatory variables collected since 1990 included age, sex, left ventricular grade (by left ventricular ejection fraction [LVEF]: grade $1 \mathrm{LVEF}>60 \%$, grade $2 \mathrm{LVEF} 40 \%-60 \%$, grade 3 LVEF 20\%-39\%, grade $4 \mathrm{LVEF}<20 \%$ ), previous $\mathrm{CABG}$, urgency of operation (elective vs semiurgent, indicating an operation during the same admission as a cardiac catheterization or a cardiac event, vs urgent, indicating an operation within 72 hours of an event, vs emergency, indicating an operation within 12 hours of an event), number of diseased coronary arteries, presence of significant stenosis $(>50 \%)$ of the left main coronary artery, and severity of angina. LVEF was determined semiquantitatively by contrast ventriculography. Echocardiography and nuclear ventriculography were carried out in an increasing proportion of patients during the course of this study, and when these additional data were available, the value for LVEF obtained closest to the date of operation was used for subsequent analysis.

Other explanatory variables collected to more fully characterize these patients included recent myocardial infarction, diabetes, peripheral vascular disease, previous coronary angioplasty or stenting, a history of hypertension, and preoperative stroke or transient ischemic attack.

Our data collection also included details of cardioplegia temperature (warm $\left[36^{\circ} \mathrm{C}-37^{\circ} \mathrm{C}\right]$, tepid $\left[29^{\circ} \mathrm{C}-30^{\circ} \mathrm{C}\right]$, or cold) and continuity (intermittent or continuous), as well as direction of administration (antegrade, retrograde, or both). Details of this database have been published elsewhere. ${ }^{14}$

\section{Analysis}

Data were collected and managed in a Microsoft Access database (Microsoft Corporation, Redmond, Wash). All statistical analyses were performed with SAS version 8.2 software for Windows (SAS Institute, Inc, Cary, NC). ${ }^{15}$ Univariate analyses were performed with $\chi^{2}$ analysis or Fisher exact test as appropriate for categoric variables. Analysis of continuous variables was carried out by analysis of variance. Variables that had a univariate $P$ value $<.25$ or those judged to be clinically important were submitted to a logistic regression model by stepwise selection. Multivariate logistic regression methods were used to calculate risk-adjusted mortality and factor-adjusted odds ratios. Model discrimination was evaluated by the area under the receiver-operator characteristic curve, ${ }^{16,17}$ and calibration was assessed with the HosmerLemeshow goodness-of-fit statistic. ${ }^{18}$ For goodness of fit, the null hypothesis is that the model fits the data. Therefore a nonsignificant $P$ value is desired, because a lower one would indicate a poor fit between predicted and observed results.

\section{Evaluation of Temporal Trends}

Rather than building a complex model to assess the temporal trends in prevalence, risk profiles, and outcomes, we used a simpler approach based on risk stratification and contingency table analysis. To examine the effect of time on patient risk profiles and outcomes, we divided patients into three groups according to the year of operation (1990-1993, 1994-1997, 1998-2001). Contingency table analysis was then used to evaluate changes with time in prevalences of preoperative risk factors, intraoperative events, and operative outcomes.

\section{Results \\ Demographic Characteristics}

A total of 18,041 patients underwent isolated CABG surgery between January 1, 1990, and December 31, 2001, at the Toronto General Hospital. The number of patients undergoing operation increased progressively during this period. Trends in patient demographic characteristics are depicted in Table 1A. The number of patients undergoing semiurgent surgery (surgery during the same hospitalization as a myocardial infarction or cardiac catheterization) increased progressively, whereas the number of patients undergoing either elective, urgent, or truly emergency surgery decreased. The prevalence of patients with moderate (LVEF $20 \%-39 \%$ ) or severe (LVEF $<20 \%$ ) left ventricular dysfunction increased slightly between the first $(23.8 \%)$ and the second $(25.2 \%)$ time cohorts but decreased in the third cohort (21.4\%). The prevalence of reoperative CABG surgery declined through the last decade as well. The changing risk profile of patients undergoing $\mathrm{CABG}$ during this 12year span is depicted in Figure 1.

\section{Intraoperative Data}

Intraoperative details are listed in Table 1B. Patients undergoing a primary operation had a left internal thoracic artery graft used routinely. There was also an increase in the use of other arterial grafts, including the right internal thoracic and 
TABLE 1A. Distribution of preoperative variables for each time cohort

\begin{tabular}{|c|c|c|c|c|}
\hline Variable & $1990-1993$ & 1994-1997 & 1998-2001 & $P$ value \\
\hline No. of patients & 5171 & 5977 & 6893 & \\
\hline \multicolumn{5}{|l|}{ Age (y) } \\
\hline Mean $\pm S D$ & $61.4 \pm 9.7$ & $62.6 \pm 9.9$ & $63.5 \pm 10$ & $<.0001$ \\
\hline Less than $65(\%)$ & 59.7 & 52.9 & 50.3 & $<.0001$ \\
\hline $65-74(\%)$ & 33.1 & 36.6 & 35.9 & \\
\hline$\geq 75(\%)$ & 7.1 & 10.5 & 13.7 & \\
\hline Female $(\%)$ & 19.7 & 22.2 & 21.3 & .005 \\
\hline Diabetes mellitus (\%) & 23.6 & 25.4 & 30.9 & $<.0001$ \\
\hline Hypertension (\%) & 50.7 & 51.8 & 57.9 & $<.0001$ \\
\hline Hyperlipidemia (\%) & 51.6 & 61.5 & 72.3 & $<.0001$ \\
\hline Positive family history (\%) & 67.6 & 63.5 & 61.7 & $<.0001$ \\
\hline \multicolumn{5}{|l|}{ Angina $(\%)$} \\
\hline Stable & 37.8 & 32.6 & 35.1 & $<.0001$ \\
\hline Crescendo & 34.2 & 30.6 & 33.2 & \\
\hline Acute coronary insufficiency & 26.3 & 34.6 & 29.6 & \\
\hline Preoperative myocardial infarction (\%) & 16.2 & 18.2 & 21.2 & $<.0001$ \\
\hline Preoperative cardiogenic shock (\%) & 1.2 & 1.2 & 1.3 & .9 \\
\hline Congestive heart failure $(\%)$ & 7.8 & 9.4 & 9.4 & .003 \\
\hline Preoperative intra-aortic balloon pump (\%) & 3.6 & 3.8 & 3 & .03 \\
\hline \multicolumn{5}{|l|}{ LVEF $(\%)$} \\
\hline$>60 \%$ & 33.3 & 26.7 & 37.6 & $<.0001$ \\
\hline $40 \%-60 \%$ & 42.9 & 48.0 & 40.9 & \\
\hline $20 \%-40 \%$ & 20.7 & 21.9 & 19.1 & \\
\hline$<20 \%$ & 3.1 & 3.3 & 2.3 & \\
\hline Left main disease $(\%)$ & 17.4 & 19.9 & 19.4 & .003 \\
\hline Triple-vessel disease (\%) & 71.6 & 75.7 & 75.9 & $<.0001$ \\
\hline Preoperative stroke $(\%)$ & 8.4 & 8.6 & 8.6 & .9 \\
\hline Peripheral vascular disease (\%) & 13.5 & 15.8 & 15.8 & .0005 \\
\hline Reoperative cardiac surgery $(\%)$ & 7.4 & 6.6 & 4.2 & $<.0001$ \\
\hline Reoperative CABG $(\%)$ & 7.2 & 6.4 & 3.9 & $<.0001$ \\
\hline $\begin{array}{l}\text { Previous percutaneous intervention with or } \\
\text { without stent }\end{array}$ & 9.7 & 10.5 & 8.4 & .0002 \\
\hline \multicolumn{5}{|l|}{ Urgency of surgery $(\%)$} \\
\hline Elective & 58.7 & 50.8 & 49.1 & $<.0001$ \\
\hline Semiurgent (ward) & 18.7 & 31.3 & 38.7 & \\
\hline Semiurgent (coronary care unit) & 2.1 & 3.6 & 3.6 & \\
\hline Urgent or emergency (coronary care unit) & 18.3 & 13.2 & 8.1 & \\
\hline $\begin{array}{l}\text { Emergency (catheterization laboratory, } \\
\text { emergency department) }\end{array}$ & 2.1 & 1.1 & 0.5 & \\
\hline
\end{tabular}

radial arteries in more recent years. Intermittent cold antegrade cardioplegia was still the most commonly used technique of myocardial protection in patients undergoing isolated CABG from 1990 to 2001. The period from 1994 to 1997 saw increased use of warm or tepid cardioplegia, but that has generally been limited to specific cases of difficult myocardial protection or cold agglutinins in the last few years.

\section{Outcomes}

Overall in-hospital mortality among patients undergoing isolated $\mathrm{CABG}$ declined significantly during the period of 12 years, from $2.4 \%$ in the first cohort to $1.2 \%$ in the last cohort of 6893 patients. The prevalences of most postoperative complications are presented in Table 1C and Figure 2. The durations of ventilation and intensive care unit and hospital stays all declined significantly from 1990 to 2001 (Table 1C).

\section{Predictors of In-hospital Mortality}

Independent predictors of in-hospital mortality. Stepwise multivariate logistic regression analysis of the 18,041 patients undergoing operation during the entire 12-year period of study showed that increasing age, female gender, hypertension, diabetes, cardiogenic shock, congestive heart failure, peripheral vascular disease, reoperative $\mathrm{CABG}$ and left main disease independently predicted in-hospital mortality (Table 2). Poor left ventricular function (left ventricular grade 4 odds ratio $4.7,95 \%$ confidence interval [CI] 3.0-7.6]) carried the greatest increase in operative risk. Patients transferred on an emergency basis from the cardiac catheterization laboratory, coronary care unit, or emergency 


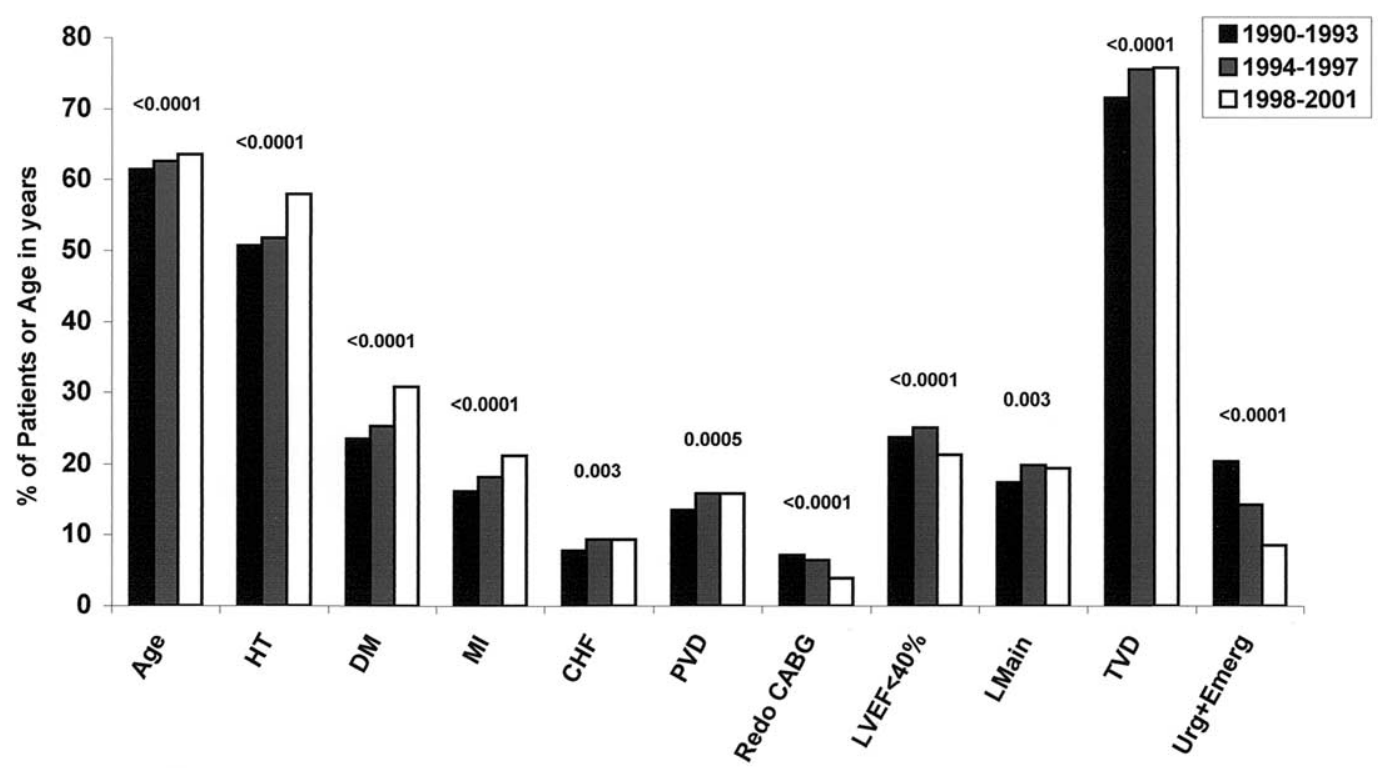

Figure 1. Risk profile of patients undergoing isolated CABG during 3 periods (1990-1993, 1994-1997, 1998-2001). Patient age, hypertension (HT), diabetes mellitus (DM), preoperative myocardial infarction (MI), congestive heart failure (CHF), peripheral vascular disease (PVD), and triple-vessel disease (TVD) increased significantly with time. Reoperative CABG, patients with poor LVEF $(<40 \%)$, and urgent and emergency operations (Urg+Emerg) decreased significantly in the 1998 to 2001 time cohort. LMain, Left main disease.

TABLE 1B. Distribution of intraoperative variables for each time cohort

\begin{tabular}{|c|c|c|c|c|}
\hline Variable & $1990-1993$ & 1994-1997 & 1998-2001 & $P$ value \\
\hline Left internal thoracic artery use (\%) & 81.4 & 88.8 & 89.3 & $<.0001$ \\
\hline Right internal thoracic artery use $(\%)$ & 2.2 & 2.7 & 6.1 & $<.0001$ \\
\hline Radial artery use* $(\%)$ & - & - & 5.4 & - \\
\hline No. of grafts & $3.4 \pm 0.9$ & $3.7 \pm 0.9$ & $3.5 \pm 0.9$ & $<.0001$ \\
\hline Duration of cardiopulmonary bypass (min) & $87.3 \pm 26.9$ & $84 \pm 29.8$ & $84.1 \pm 33.8$ & $<.0001$ \\
\hline Duration of crossclamping (min) & $59.7 \pm 18.6$ & $62.2 \pm 18.6$ & $62.4 \pm 25.1$ & $<.0001$ \\
\hline \multicolumn{5}{|l|}{ Cardioplegia technique $(\%)$} \\
\hline Intermittent cold antegrade & 76.8 & 67.1 & 74.8 & $<.0001$ \\
\hline Continuous cold antegrade/retrograde & 8.2 & 13.7 & 9 & \\
\hline Warm or tepid cardioplegia & 14.8 & 18.8 & 9.4 & \\
\hline On pump, no crossclamp & 0.1 & 0.1 & 0.4 & \\
\hline Off pump & 0.1 & 0.4 & 6.4 & \\
\hline
\end{tabular}

*Radial artery use data for 1990-1993 and 1994-1997 time cohort were not available.

department were also at markedly increased risk of death (odds ratio 4.0, 95\% CI 2.1-7.4) relative to those undergoing elective surgery. As anticipated, earlier year of operation was also an independent risk factor for mortality.

Changing trends in multivariate risk factors and inhospital mortality. Although some predictors of in-hospital mortality remained constant throughout the three-year groups, there have been important changes in some of these predictors (Table 3). The unadjusted in-hospital mortalities for individual predictors are shown in Figure 3.

AGE AND GENDER. Age and female gender were predictors of in-hospital mortality through all three periods. Patients
75 years old and older had higher in-hospital mortality than those younger than 75 years, but the mortality within the group of elderly patients decreased significantly from $6.8 \%$ in the first time cohort to $2.5 \%$ in the last cohort. Similar, if lesser, reductions in mortality were also noted in the younger ( $\leq 65$ years) age groups (falling from $1.3 \%$ in the first cohort to $0.8 \%$ in the last cohort). Female patients had consistently higher mortality than male patients, but inhospital mortality among female patients fell from $4.1 \%$ in the first time cohort to $2.1 \%$ in the last cohort.

TIMING OF SURGERY. Patients requiring urgent or emergency surgery from the cardiac catheterization laboratory or 


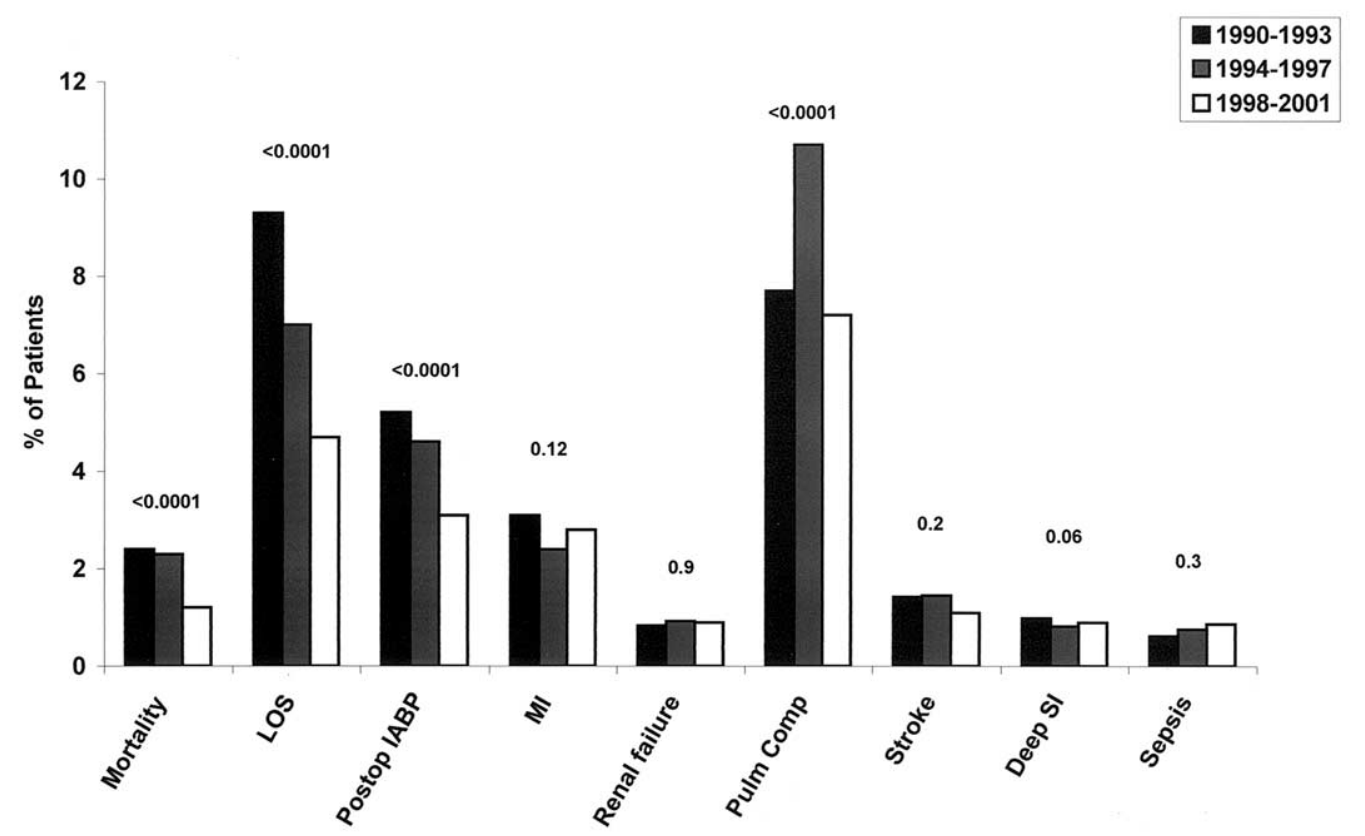

Figure 2. Trends in hospital outcomes: operative mortality, low-output syndrome (LOS), postoperative intra-aortic balloon pump (IABP) use, perioperative myocardial infarction (MI), postoperative renal failure, pulmonary complications (Pulm Comp), stroke, deep sternal infections (Deep SI), and sepsis.

TABLE 1C. Distribution of postoperative outcomes for each time cohort

\begin{tabular}{|c|c|c|c|c|}
\hline Variable & $1990-1993$ & 1994-1997 & 1998-2001 & $P$ value \\
\hline Mortality $(\%)$ & 2.4 & 2.3 & 1.2 & $<.0001$ \\
\hline Inotrope use $>30 \min (\%)$ & 28.5 & 34.7 & 32.9 & $<.0001$ \\
\hline Low-output syndrome $(\%)$ & 9.3 & 7 & 4.7 & $<.0001$ \\
\hline Postoperative intra-aortic balloon pump (\%) & 5.2 & 4.6 & 3.1 & $<.0001$ \\
\hline Postoperative myocardial infarction $(\%)$ & 3.1 & 2.4 & 2.8 & .1 \\
\hline Postoperative stroke (\%) & 1.4 & 1.4 & 1.1 & .2 \\
\hline Postoperative renal failure $(\%)$ & 0.8 & 0.9 & 0.9 & .9 \\
\hline Postoperative pulmonary complications (\%) & 7.7 & 10.7 & 7.2 & $<.0001$ \\
\hline \multicolumn{5}{|l|}{ Sternal wound infection $(\%)$} \\
\hline Superficial & 2.2 & 1.6 & 1.5 & \multirow[t]{2}{*}{.06} \\
\hline Deep & 0.9 & 0.8 & 0.9 & \\
\hline Sepsis & 0.6 & 0.7 & 0.9 & .3 \\
\hline Resternotomy for bleeding (\%) & 1.4 & 1.6 & 2.6 & $<.0001$ \\
\hline Transfused patients (\%) & - & 40.2 & 44 & $<.0001$ \\
\hline Units of packed red blood cells transfused & - & $1.1 \pm 2.4$ & $1.2 \pm 3.1$ & $<.0001$ \\
\hline Duration of ventilation (h) & $30.4 \pm 66.2$ & $14.4 \pm 48.9$ & $14.8 \pm 49.5$ & $<.0001$ \\
\hline Duration of intensive care unit stay (h) & $59.2 \pm 78.2$ & $42.4 \pm 78.8$ & $45.7 \pm 79.2$ & $<.0001$ \\
\hline Postoperative hospital stay (d) & $10 \pm 6.6$ & $8.1 \pm 6.5$ & $7.6 \pm 5.7$ & $<.0001$ \\
\hline
\end{tabular}

the emergency department were also at increased risk. Although the number of patients requiring emergency surgical revascularization decreased with time, the odds ratio associated with emergency surgery was increased significantly in the last time cohort (odds ratio 19.0, 95\% CI 5.0-72.1). Whereas in-hospital mortality among patients undergoing elective or semiurgent surgery declined significantly during the 12-year span of this study, mortality among the decreas- ing number of patients undergoing emergency surgery was almost doubled from the first cohort $(6.5 \%)$ to the last cohort $(12.5 \%)$.

LVEF. Severe left ventricular dysfunction (LVEF <20\%) was the most significant predictor of in-hospital mortality in the entire cohort of 18,041 patients. This was also true of the first and second time cohorts, although the odds ratios associated with a LVEF less than $20 \%$ decreased from 7.1 
TABLE 2. Multivariable predictors of hospital mortality in 18041 patients undergoing isolated CABG operations from 1990 through 2001

\begin{tabular}{|c|c|c|c|c|c|}
\hline Variable & $\mathbf{n}$ & $\begin{array}{l}\text { Regression } \\
\text { coefficient }\end{array}$ & $\begin{array}{l}\text { Odds } \\
\text { ratio }\end{array}$ & 95\% CI & $P$ value \\
\hline Constant & & $-8.99 \pm 0.49$ & & & \\
\hline $\mathrm{Age}^{*}$ & - & $0.05 \pm 0.01$ & 1.1 & $1.0-1.1$ & $<.0001$ \\
\hline Female gender & 3811 & $0.54 \pm 0.12$ & 1.7 & $1.3-2.2$ & $<.0001$ \\
\hline Hypertension & 9695 & $0.40 \pm 0.12$ & 1.5 & $1.2-1.9$ & .001 \\
\hline Diabetes & 4866 & $0.27 \pm 0.12$ & 1.3 & $1.0-1.7$ & .03 \\
\hline Cardiogenic shock & 219 & $0.76 \pm 0.26$ & 2.2 & $1.3-3.6$ & .004 \\
\hline Congestive heart failure & 1610 & $0.44 \pm 0.16$ & 1.6 & $1.1-2.1$ & .006 \\
\hline Peripheral vascular disease & 2728 & $0.59 \pm 0.13$ & 1.8 & $1.4-2.3$ & $<.0001$ \\
\hline Reoperative CABG & 1025 & $1.09 \pm 0.17$ & 3.0 & $2.2-4.2$ & $<.0001$ \\
\hline Left main disease & 3426 & $0.36 \pm 0.13$ & 1.4 & $1.1-1.8$ & .004 \\
\hline \multicolumn{6}{|l|}{ LVEF } \\
\hline$<20 \%$ & 513 & $1.56 \pm 0.24$ & 4.7 & $3.0-7.6$ & $<.0001$ \\
\hline $20 \%-40 \%$ & 3694 & $0.58 \pm 0.18$ & 1.8 & $1.2-2.5$ & .001 \\
\hline $40 \%-60 \%$ & 7899 & $0.32 \pm 0.16$ & 1.4 & $1.0-1.9$ & .05 \\
\hline \multicolumn{6}{|l|}{ Urgency of surgery } \\
\hline Semiurgent (ward) & 5487 & $0.18 \pm 0.15$ & 1.2 & $0.9-1.6$ & .2 \\
\hline Semiurgent (coronary care unit) & 570 & $0.85 \pm 0.24$ & 2.3 & $1.5-3.7$ & .0004 \\
\hline $\begin{array}{l}\text { Urgent or emergency (coronary } \\
\text { care unit) }\end{array}$ & 2277 & $0.69 \pm 0.16$ & 2.0 & $1.5-2.7$ & $<.0001$ \\
\hline $\begin{array}{l}\text { Emergent (catheterization } \\
\text { laboratory, emergency } \\
\text { department) }\end{array}$ & 206 & $1.38 \pm 0.32$ & 4.0 & 2.1-7.4 & $<.0001$ \\
\hline Year of operation 1998-2001‡ & 6893 & $-0.79 \pm 0.15$ & 0.4 & $0.3-0.6$ & $<.0001$ \\
\hline Year of operation 1994-1997‡ & 5977 & $-0.18 \pm 0.13$ & 0.8 & $0.6-1.1$ & .2 \\
\hline
\end{tabular}

The area under the ROC curve was 0.8. The Hosmer-Lemeshow goodness-of-fit $P$ value was 25 .

${ }^{*}$ Age is a continuous variable.

tOdds ratios were calculated by comparing against LVEF $>60 \%$.

$\ddagger 0$ dds ratios were calculated by comparing against the 1990-1993 time cohort.

in the first cohort to 5.1 in the second cohort. However, left ventricular dysfunction was no longer a significant predictor of in-hospital mortality in the last time cohort, despite a larger number of patients. When LVEF was forced into the model for the 1998 to 2001 period, the resulting $P$ value for it was .07 . Patients with the most severe left ventricular dysfunction (LVEF <20\%) had approximately 3 times greater in-hospital mortality than those with LVEF between $20 \%$ and $40 \%$ in the first two time cohorts. As the results in patients with mild or moderate left ventricular dysfunction improved even further, this ratio increased to approximately 7 in the last cohort. Overall in-hospital mortality for patients with severe left ventricular dysfunction declined, however, from $10.8 \%$ in 1990 to 1993 to $8.9 \%$ in 1998 to 2001 .

REOPERATIVE CABG. Patients undergoing reoperative CABG were also at a higher risk of dying in the first time cohort (odds ratio 4.2, 95\% CI 2.5-6.8), but the relative risk fell by almost half from the 1990 to 1993 period to the 1994 to 1997 time cohort (odds ratio 2.3, 95\% CI 1.3-3.8) and remained about the same in the 1998 to 2001 period (odds ratio $2.7,95 \%$ CI 1.2-6.1).

CONGESTIVE HEART FAILURE AND CARDIOGENIC SHOCK. Congestive heart failure was a predictor in the last two time cohorts, and cardiogenic shock was a predictor only in the 1998 to 2001 cohort. The number of patients in congestive heart failure undergoing $\mathrm{CABG}$ increased significantly during the last decade, and in-hospital mortality for these patients decreased only minimally, from $6 \%$ to $5.1 \%$. In contrast, mortality among patients in cardiogenic shock increased from $10.9 \%$ in the 1990 to 1993 period to $16.3 \%$ in the 1998 to 2001 time cohort.

LEFT MAIN DISEASE. Although in-hospital mortality among patients with left main disease was consistently higher than that in patients with triple-vessel disease but without left main stenosis, mortality among these patients fell during the 12-year period, from $3.4 \%$ to $2.4 \%$.

\section{Discussion}

The steadily improving results of $\mathrm{CABG}$ have been reported extensively ${ }^{2,6-9,19}$ since the Coronary Artery Surgery Study first demonstrated the advantages of surgical revascularization. ${ }^{20-22}$ In the ensuing decades, cardiac surgeons worldwide have witnessed a steady increase in the risk profiles of patients referred for $\mathrm{CABG}$, related to improved outcomes in older ${ }^{11,23}$ and sicker patients, ${ }^{2,19,23}$ the selection of lower risk patients for percutaneous intervention, ${ }^{24}$ and evidence 
that patients with left ventricular dysfunction often benefit the most from surgical intervention. ${ }^{24}$

\section{Increasing Risk Profile}

As anticipated in this study, we also found that the prevalence of risk factors and comorbidities that have consistently predicted in-hospital mortality in previous studies ${ }^{1,2,6,14,19}$ increased significantly during the entire period of this study. These factors included advanced age, female gender, diabetes, and hypertension. Patients were increasingly likely to be seen with acute coronary insufficiency, a recent preoperative myocardial infarction, cardiogenic shock, or congestive heart failure. Coronary anatomy in these patients worsened through the decade, with the prevalences of left main disease and triple-vessel disease increasing steadily. Noncardiac comorbidities, such as peripheral vascular disease, also increased with time.

\section{Predictors of Mortality}

The independent predictors of in-hospital mortality in these 18,041 patients (increasing age, female gender, hypertension, diabetes, cardiogenic shock, congestive heart failure, peripheral vascular disease, reoperative $\mathrm{CABG}$, left main disease, decreasing LVEF, and urgent or emergency surgery) are generally similar to those previously described by Christakis and colleagues, ${ }^{6}$ who had observed that reoperative CABG, LVEF, and urgency of surgery were the most significant predictors of in-hospital mortality. Jones and associates, ${ }^{25}$ in a review of seven data sets, reported that seven variables (age, gender, previous heart surgery, left main stenosis, extent of coronary artery disease, LVEF, and urgency of operation) predicted mortality after CABG. The predictive power of these factors was greatest for urgency of surgery, age, and previous CABG. Abramov and colleagues ${ }^{2}$ also identified urgency of operation (odds ratio 4.5), reoperative procedure (odds ratio 3.7), and LVEF less than $35 \%$ (odds ratio 3.2) as the most significant predictors of in-hospital mortality. As anticipated, year of operation was an independent predictor of in-hospital mortality in our series, with an odds ratio of 0.4 (95\% CI 0.3-0.6) for the third time cohort relative to the first and an odds ratio of 0.8 (95\% CI 0.6-1.1) for the second cohort relative to the first.

Reoperative CABG. Despite the commonly held assumption that the prevalence of reoperative CABG would increase, we observed a steady decrease during the 12-year period of study in the number of patients undergoing second or third CABG operations, from $7.4 \%$ in the first time cohort to $4.2 \%$ in the last cohort. A similar, but less marked, trend was also observed by Ferguson and coworkers ${ }^{19}$ in the Society of Thoracic Surgeons National Database (falling from $10.6 \%$ in 1990 to $8.4 \%$ in 1999). In contrast, Abramov and colleagues ${ }^{2}$ reported a relatively unchanged prevalence of reoperations from $2.2 \%$ in 1990 to 1992 to $2.9 \%$ in 1996
TABLE 3. Changing trends in multivariate risk factors by year group (odds ratios)

\begin{tabular}{lccc}
\hline & 1990-1993* $^{\text {1994-1997† }}$ & 1998-2001‡ \\
\hline Age & 1.064 & 1.057 & 1.038 \\
Female sex & 1.8 & 1.6 & 1.9 \\
Emergency surgery§ & 4.1 & 3.9 & 19.0 \\
Diabetes & 1.9 & - & - \\
Hypertension & - & 1.6 & - \\
Peripheral vascular disease & 3.0 & - & - \\
Reoperative CABG & 4.2 & 2.3 & 2.7 \\
LVEF <20\% & 7.1 & 5.1 & - \\
LVEF 20\%-40\% & 1.9 & 2.4 & - \\
Congestive heart failure & - & 1.9 & 3.6 \\
Cardiogenic shock & - & - & 3.3 \\
Left main disease & - & - & 1.7
\end{tabular}

*The area under the ROC curve was 0.82. The Hosmer-Lemeshow goodness-of-fit $P$ value was .53.

tThe area under the ROC curve was 0.77 . The Hosmer-Lemeshow goodness-of-fit $P$ value was .31.

$\ddagger$ The area under the ROC curve was 0.83 . The Hosmer-Lemeshow goodness-of-fit $P$ value was .37.

$\S$ Emergency patients from catheterization laboratory or emergency units of same or other hospitals.

to 1998 . The decline in reoperations at our institution may have been due to later presentation for initial operation (consistent with the increasing age of patients undergoing surgery and perhaps increasing percutaneous interventions before surgery), more aggressive percutaneous intervention in patients with graft atherosclerosis, or perhaps greater graft longevity with the widespread use of statins.

The in-hospital mortality among patients undergoing reoperative surgery also declined with time, with the odds ratio associated with reoperative $\mathrm{CABG}$ declining by approximately $50 \%$ from the first to the second time cohorts. Improved perioperative care and the increasing use of retrograde cardioplegia most likely accounted for this fall in in-hospital mortality. ${ }^{26}$ Stephan and colleagues ${ }^{27}$ reported a mortality of $7.3 \%$ in 164 patients undergoing elective coronary reoperations, which was similar to our early experience. Shimada and coworkers ${ }^{28}$ reported outstanding results in a series of 200 reoperations, with an in-hospital mortality of only $2.5 \%$, similar to our results in the most recent cohort.

$\boldsymbol{L V E F}$. The prevalence of patients with LVEF $40 \%$ or lower fluctuated, but only slightly, among the three time cohorts, whereas in-hospital mortality in this group fell by $50 \%$ during the span of this series. The slight decrease in the prevalence of LVEF less than $20 \%$ in the last cohort may have been due to, among other potential explanations, (1) an increasing number of patients with acute myocardial infarction undergoing primary percutaneous transluminal coronary angioplasty and stenting, thus preventing deterioration of left ventricular function, or (2) reduced referral of patients with severe left ventricular dysfunction in favor of 


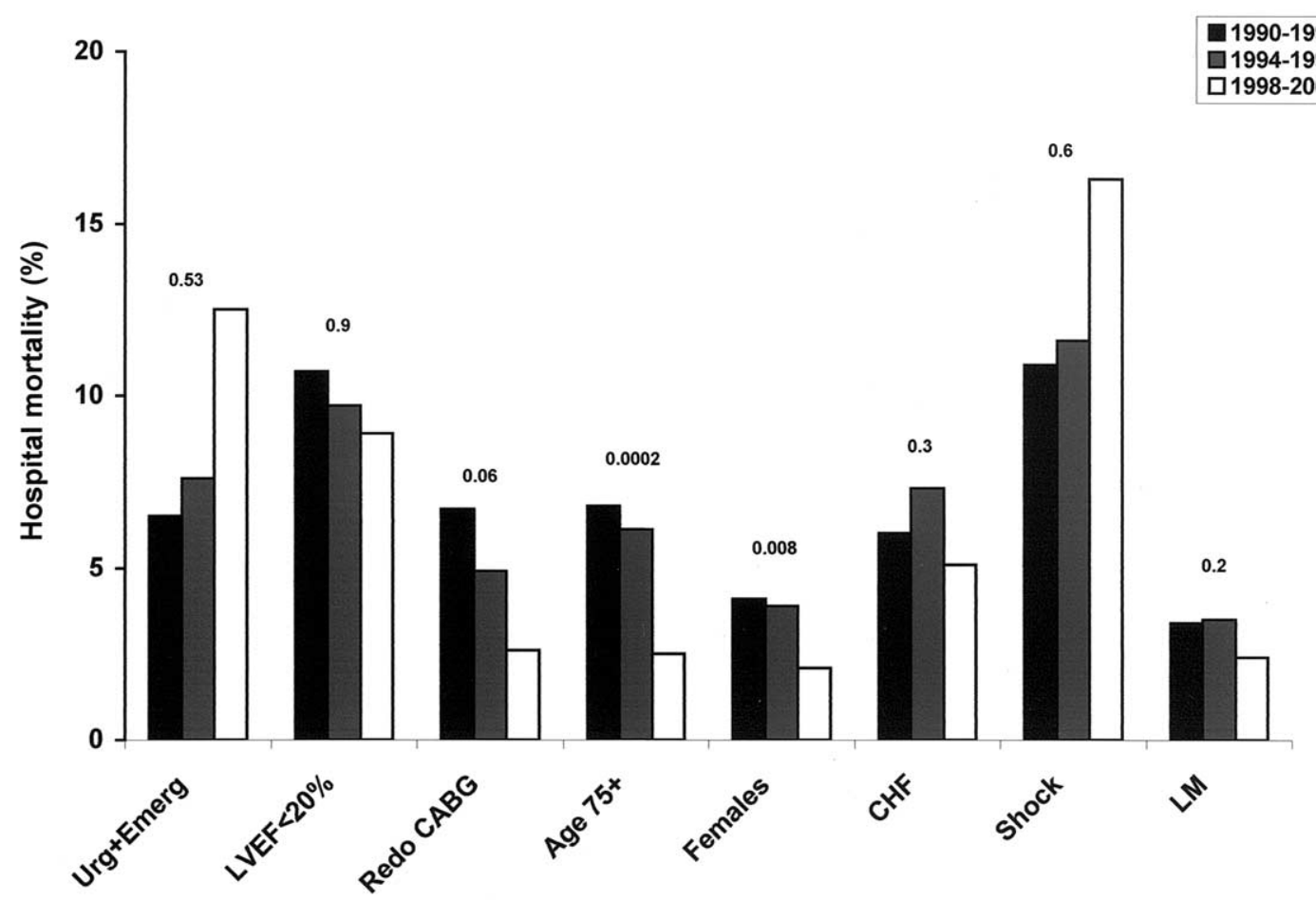

Figure 3. Observed operative mortality for patients undergoing urgent or emergency CABG (Urg+Emerg) and reoperative (Redo) CABG, patients with LVEF less than $\mathbf{2 0 \%}$, patients 75 years old or older, female patients, and patients with congestive heart failure (CHF), cardiogenic shock, and left main disease (LM).

percutaneous interventions. The mortality associated with moderate left ventricular dysfunction fell to the point $(3.2 \%$ in the first cohort, odds ratio 1.9 , to $1.4 \%$ in the last cohort, odds ratio 0.9 ) that only an ejection fraction less than $20 \%$ is now considered to be a finding of clinical importance in our practice. Whereas severe left ventricular dysfunction was the most significant predictor of in-hospital mortality in the first two time cohorts, with odds ratios of 7.1 and 5.1, respectively, it did not emerge as a statistically significant predictor in the last cohort. This is not to say that left ventricular dysfunction did not influence mortality among patients operated on in 1998 to 2001; rather, its influence had declined to the point that, even in a reasonably large cohort of 6893 patients, its effect was now insufficient to reach statistical significance in multivariable modeling. When LVEF was forced into the model for the last time cohort, the $P$ value for LVEF (.07) was marginally higher than the cutoff threshold of .05 , and the odds ratio had declined to 2.8 from its previous high of 7.1 in the first cohort. This represents a significant departure from its previously consistent status as the most significant predictor of mortality in any analysis.

This remarkable decline in the predictive value of left ventricular dysfunction may be partly due to the decreasing prevalence of patients with LVEF less than $20 \%$ in the last time cohort. However, the odds ratio for mortality associated with LVEF less than $20 \%$ also fell dramatically, indicating that outcomes improved in parallel with the modest reduction in the prevalence of severe left ventricular dysfunction. We believe that the improvement in survival of this group of patients was due to the cumulative beneficial impact of various techniques and strategies used during the last decade. Early extubation anesthetic management provided stable perioperative hemodynamics, reduced catecholamine stress response, improved intrapulmonary shunt fraction, and allowed earlier mobilization of patients. The use of mild systemic hypothermia in all cases and retrograde tepid or warm cardioplegia in selected high-risk cases may also have contributed to improved outcomes. Perioperative usage of antifibrinolytic agents increased, and a strict transfusion protocol was adopted. The use of epiaortic and transesophageal echocardiography in patients with a high probability of aortic atherosclerosis or left ventricular thrombi may have reduced the risk of perioperative stroke.

Left main disease. The prevalence of left main disease increased slightly from the first to the last time cohorts. Although the in-hospital mortality in this group of patients fell during the 12 -year period, from $3.4 \%$ to $2.4 \%$, left main disease was a significant predictor (odds ratio 1.7) of inhospital mortality only in the last cohort. This somewhat 
counterintuitive finding may reflect a persistent but more subtle predictive effect of left main disease (overall odds ratio 1.4 in the 12-year period) that was "unmasked" in the last time cohort as previously more powerful predictors like left ventricular dysfunction and reoperative surgery declined in importance.

Age. The prevalence of elderly patients ( $\geq 75$ years of age) undergoing $\mathrm{CABG}$ almost doubled from the first to the last time cohort, but in-hospital mortality in this group fell from $6.8 \%$ to $2.5 \%$. Although age was a consistent predictor of in-hospital mortality in all three time cohorts, the odds ratio for age fell from 1.064 in the first cohort to 1.038 in the last group. This difference in numbers seems small, but the compounding effect of this incremental risk per year of increasing age means that a substantial reduction in agerelated risk was achieved. A similar reduction in mortality has also been reported by Ivanov and colleagues ${ }^{11}$ from 1982 to 1996, despite an increasing risk profile among these elderly patients.

Urgency of surgery. The percentage of patients referred for urgent and emergency CABG declined significantly from $20.4 \%$ in the first cohort to $8.6 \%$ in the last one, whereas the proportion of patients requiring semiurgent surgery (during the same admission) rose steadily. Ferguson and coworkers ${ }^{19}$ found similar trends, with a reduction in emergency and salvage operations (7.1\% in 1990 to $5.5 \%$ in $1999)$ and a rise in the number of urgent operations (17.6\% in 1990 to $32.9 \%$ in 1999). Abramov and colleagues ${ }^{2}$ also reported an increase in the number of urgent operations from $26.5 \%$ in 1990 to 1992 to $41.5 \%$ in 1996 to 1998 .

In our series the proportion of patients requiring truly emergency CABG (transferred directly from the cardiac catheterization laboratory) decreased from $2.1 \%$ to $0.5 \%$. This decline was likely related to the aggressive use of "bailout" stents and perhaps to the increased use of glycoprotein IIb and IIIa inhibitors. The need for emergency surgery was associated with a significantly increased risk of mortality in all three time cohorts, but the odds ratio increased dramatically with time (rising to 19.0 in the last cohort), even as the number of patients in this subgroup fell from 108 in the first time cohort to 32 in the last. In a trend that paralleled that observed for patients undergoing CABG in general, patients who had complications or became unstable in the cardiac catheterization laboratory but who could be rescued by glycoprotein IIb and IIIa inhibitors or stents were removed from this surgical cohort. The remainder of these patients, referred after these percutaneous attempts at rescue had also failed, increasingly represented a scenario of "salvaging the unsalvageable."

Time. In this series, overall in-hospital mortality among patients undergoing isolated CABG decreased from $2.4 \%$ in the 1990 to 1993 time cohort to $1.2 \%$ in 1998 to 2001, a reduction of $50 \%$. A similar reduction of $52 \%$ in risk- adjusted mortality in cardiac surgical centers in Ontario was observed between 1986 and 1995. ${ }^{29}$ Abramov and colleagues ${ }^{2}$ reported a reduction in risk-adjusted in-hospital mortality from $2.5 \%$ to $1.8 \%$, and Ferguson and coworkers $^{19}$ reported a relative decrease of $23 \%$ in in-hospital mortality in the Society of Thoracic Surgeons database during the course of a decade. Other studies from New York, ${ }^{8}$ northern New England, ${ }^{30}$ and Massachusetts ${ }^{10}$ have also reported decreasing in-hospital mortality after CABG. In contrast, Warner and associates ${ }^{23}$ studied the effects of patient characteristics on outcomes from 1981 to 1995 and found that mortality increased from $2.4 \%$ to $3.4 \%$, a finding that was attributed to a learning curve associated with the shift toward higher risk patients.

\section{Conclusions}

Our current study illustrates the ever-changing nature of CABG. With steadily improving results in progressively sicker patients, it is now routine at many tertiary and quaternary referral centers to operate on, and achieve superb results with, patients who a decade ago would have posed extreme risks. Although we did note a steady increase in the risk profile of patients undergoing surgery during the course of this study, it is not possible to determine whether even higher risk patients with the greatest left ventricular dysfunction or previous surgery were diverted to percutaneous procedures, because our database does not track patients turned down for surgery or those preferentially referred for percutaneous intervention by the cardiologist. The trends that we observed in this study, however, along with the overall in-hospital mortality of $1.2 \%$ among the 6893 patients in the most recent cohort, suggest to us that advances in perioperative management, technology, and the increasing experience in managing such patients have dramatically reduced the risk associated with even severe left ventricular dysfunction and reoperative surgery. In contrast, patients requiring truly emergency $\mathrm{CABG}$ face a greatly increased risk of death.

\section{References}

1. Sadeghi N, Sadeghi S, Mood ZA, Karimi A. Determinants of hospital mortality following primary coronary artery bypass surgery. Eur J Cardiothorac Surg. 2002;21:187-92.

2. Abramov D, Tamariz MG, Fremes SE, Guru V, Borger MA, Christakis GT, et al. Trends in coronary artery bypass surgery results: a recent, 9-year study. Ann Thorac Surg. 2000;70:84-90.

3. Noyez L, Janssen DP, van Druten JA, Skotnicki SH, Lacquet LK. Coronary bypass surgery: what is changing? Analysis of 3834 patients undergoing primary isolated myocardial revascularization. Eur J Cardiothorac Surg. 1998;13:365-9.

4. Magovern JA, Sakert T, Magovern GJ, Benckart DH, Burkholder JA, Liebler GA, Magovern GJ Sr. A model that predicts morbidity and mortality after coronary artery bypass graft surgery. J Am Coll Cardiol. 1996;28:1147-53.

5. Katz NM, Chase GA. Risks of cardiac operations for elderly patients: reduction of age factor. Ann Thorac Surg. 1997;63:1309-14.

6. Christakis GT, Ivanov J, Weisel RD, Birnbaum PL, David TE, Salerno 
TA. The changing pattern of coronary artery bypass surgery. Circulation. 1989;80:I151-61.

7. Ugnat $\mathrm{AM}$, Naylor $\mathrm{CD}$. Trends in coronary artery bypass grafting in Ontario from 1981 to 1989. Can Med Assoc J. 1993;148:569-75.

8. Hannan EL, Kilburn H, Racz M, Shields E, Chassin MR. Improving the outcome of coronary artery bypass surgery in New York State. JAMA. 1994;271:761-6.

9. Ghali WA, Quan H, Brant R. Coronary artery bypass grafting in Canada: national and provincial mortality trends, 1992-1995. Can Med Assoc J. 1998;159:25-31.

10. Ghali WA, Ash AS, Hall RE, Moskowitz MA. Statewide quality improvement initiatives and mortality after cardiac surgery. JAMA. 1997;277:379-82.

11. Ivanov J, Weisel RD, David TE, Naylor DC. Fifteen-year trends in risk severity and operative mortality in elderly patients undergoing coronary artery bypass graft surgery. Circulation. 1998;97:673-80.

12. Peterson ED, Jollis JG, Bebchuk JD, DeLong ER, Muhlbaier LH, Mark DB, et al. Changes in mortality after myocardial revascularization in the elderly. The national Medicare experience. Ann Intern Med. 1994;121:919-27.

13. Edwards FH, Grover FL, Shroyer AL, Schwartz M, Bero J. The Society of Thoracic Surgeons National Cardiac Surgery Database: current risk assessment. Ann Thorac Surg. 1997;63:903-8.

14. Rao V, Ivanov J, Weisel RD, Ikonomidis JS, Christakis GT, David TE. Predictors of low cardiac output syndrome after coronary artery bypass. J Thorac Cardiovasc Surg. 1996;112:38-51.

15. SAS Institute. SAS/STAT user's guide, version 8. Cary (NC): SAS Institute; 1988.

16. Hanley JA, McNeil BJ. The meaning and the use of area under a receiver operating characteristic (ROC) curve. Radiology. 1982;143: 29-36.

17. Hanley JA, McNeil BJ. A method for comparing areas under receiver operating characteristic curves derived from the same cases. Radiology. 1983;148:839-43.

18. Hosmer DW, Lemeshow S. Applied logistic regression. New York: John Wiley and Sons; 1989.

19. Ferguson TB Jr, Hammill BG, Peterson ED, DeLong ER, Grover FL. A decade of change-risk profiles and outcomes for isolated coronary artery bypass grafting procedures, 1990-1999: a report from the STS National Database Committee and the Duke Clinical Research Institute. Ann Thorac Surg. 2002;73:480-9.
20. Kennedy JW, Kaiser GC, Fisher LD, Maynard C, Fritz JK, Myers W, et al. Multivariate discriminant analysis of the clinical and angiographic predictors of operative mortality from the Collaborative Study in Coronary Artery Surgery (CASS). J Thorac Cardiovasc Surg. 1980;80:876-87.

21. Kennedy JW, Kaiser GC, Fisher LD, Fritz JK, Myers W, Mudd JG, et al. Clinical and angiographic predictors of operative mortality from the Collaborative Study in Coronary Artery Surgery (CASS). Circulation. 1981;63:793-802.

22. Fisher LD, Kennedy JW, Davis KB, Maynard C, Fritz JK, Kaiser GC, et al. Association of sex, physical size and hospital mortality after coronary artery bypass in Coronary Artery Surgery Study (CASS). J Thorac Cardiovasc Surg. 1982;84:334-41.

23. Warner CD, Weintraub WS, Craver JM, Jones EL, Gott JP, Guyton RA. Effect of cardiac surgery patient characteristics on patient outcomes from 1981 through 1995. Circulation. 1997;96:1575-9.

24. Muhlbaier LH, Pryor DB, Rankin JS, Smith LR, Mark DB, Jones RH, et al. Observational comparison of event-free survival with medical and surgical therapy in patients with coronary artery disease. 20 years of follow-up. Circulation. 1992;86(5 Suppl):198-204.

25. Jones RH, Hannan EL, Hammermeister KE, Delong ER, O'Connor GT, Luepkar RV, et al. Identification of preoperative variables needed for risk adjustment of short-term mortality after coronary artery bypass graft surgery: the Working Group Panel on the Cooperative CABG Database Project. J Am Coll Cardiol. 1996;28:1478-87.

26. Yau TM, Borger MA, Weisel RD, Ivanov J. The changing pattern of reoperative coronary surgery: trends in 1230 consecutive reoperations. J Thorac Cardiovasc Surg. 2000;120:156-63.

27. Stephan WJ, O'Keefe JH Jr, Piehler JM, McCallister BD, Dahiya RS, Shimshak TM, et al. Coronary angioplasty versus repeat coronary bypass grafting for patients with previous bypass surgery. $J$ Am Coll Cardiol. 1996;28:1140-6.

28. Shimada Y, Dixit A, Fermanis G, Horton D. Reoperation for recurrent coronary artery disease: results of 200 consecutive cases. Aust $N \mathrm{Z}$ J Surg. 1998;68:729-34.

29. Tu JV, Wu K. The improving outcomes of coronary artery bypass graft surgery in Ontario, 1981 to 1995. Can Med Assoc J. 1998;159:221-7.

30. O'Connor GT, Plume SK, Olmstead EM, Morton JR, Maloney CT, Nugent WC, et al. A regional intervention to improve the hospital mortality associated with coronary artery bypass graft surgery. JAMA. 1996;275:841-6. 